\title{
Raman lidar measurements of water vapor and cirrus clouds during the passage of hurricane Bonnie
}

\author{
D. N. Whiteman, K. D. Evans, B. Demoz, D. O'C. Starr, D. Tobin, W. \\ Feltz, G. J. Jedlovec, S. I. Gutman, G. K. Schwemmer, M. Cadirola, S. \\ H. Melfi, F. J. Schmidlin
}

\begin{abstract}
The NASA/GSFC Scanning Raman Lidar (SRL) was stationed on Andros Island in the Bahamas during August - September, 1998 as a part of the third Convection and Moisture Experiment (CAMEX-3) which focussed on hurricane development and tracking. During the period August 21 - 24, hurricane Bonnie passed near Andros Island and influenced the water vapor and cirrus cloud measurements acquired by the SRL. Two drying signatures related to the hurricane were recorded by the SRL and other sensors. Cirrus cloud optical depths (at $351 \mathrm{~nm}$ ) were also measured during this period. Optical depth values ranged from approximately 0.01 to 1.4. The influence of multiple scattering on these optical depth measurements was studied with the conclusion that the measured values of optical depth are less than the actual value by up to $20 \%$. The UV/RR cirrus cloud optical depth ratio was estimated based on a comparison of lidar and GOES measurements. Simple radiative transfer model calculations compared with GOES satellite brightness temperatures indicate that satellite radiances are significantly affected by the presence of cirrus clouds if IR optical depths are approximately 0.02 or greater. This has implications for satellite cirrus detection requirements.
\end{abstract}




\section{Introduction}

Raman lidar has long been regarded as one of the leading techniques for remotely quantifying numerous atmospheric parameters including water vapor, aerosols, temperature and clouds. Due to this broad measurement capability, the NASA/GSFC Scanning Raman Lidar (SRL) was selected to participate in the NASA sponsored CAMEX-3 (third Convection and Moisture Experiment) hurricane study program which occurred during the months of August and September, 1998. The SRL was stationed on Andros Island, Bahamas during the experiment and acquired nearly daily measurements of water vapor, aerosols and clouds. SRL measurements of the variation of water vapor and cirnus clouds during the passage of hurricane Bonnie from August $21-24$ are presented here. Significant drying episodes which are likely are due to mid-troposphere subsidence are examined. Cirrus cloud optical depth are quantified after the influence of multiple scattering on optical depth measurements is estimated. Cirrus cloud optical depths measured in the ultraviolet region of the spectrum are then translated to optical depths at the 11 and 12 micron channel location of the GOES satellite. Using these IR optical depth values, the influence of hurricane-induced cirms clouds on GOES retrievals are studied by comparing radiative transfer model simulations to retrieved surface temperatures and precipitable water.

\section{CAMEX3}

Errors in prediction of hurricane track and thus landfall location are both dangerous for inhabited areas and can lead to unnecessary evacuation expense. And yet, small changes in initial atmospheric conditions can lead to large differences in the forecast of hurricane track and intensification [22]. Because of this, CAMEX-3 was sponsored by NASA's Atmospheric Dynamics and Remote Sensing Program with the goal of acquiring detailed measurements of water vapor, temperature and winds which can be used to help improve hurricane tracking and intensification model initialization and forecasting. Several instrumented aircraft were based at Patrick Air Force Base in Florida and made numerous flights in and near hurricanes Bonnie, Danielle, Earl and Georges as a part of this effort. Active and passive remote sensing instruments on board these aircraft were used to measure numerous atmospheric parameters including water vapor, winds, temperature, rainfall velocities and lightning (http://ghrc.msfc.nasa.gov/camex3/).

A highly instrumented ground station was established on Andros Island in the Bahamas at the U. S. Navy's Atlantic Undersea Test and Evaluation Center (AUTEC) as a part of CAMEX-3. Analysis of historical data indicated that the prevailing winds at AUTEC are out of the southeast during hurricane season. This indicated that this land-based location on the windward coast of the island should give a good representation of the water vapor conditions over the open ocean. In addition to the SRL, this site included a University of Wisconsin Advanced Emitted Radiance Interferometer (AERI) [10], radiosonde launches provided by both NASA/GSFC Wallops Flight Facility and University of Wisconsin, Global Positioning System (GPS) measurements of total precipitable water, Cimel sun photometer measurements of total precipitable water and aerosol optical depth at several wavelengths [23], chilled mirror hygrometer (http://www.humid.com/geiindex.html) measurements of relative humidity as well as standard ground measurements of temperature, pressure and relative humidity.

The ground station served two main functions during CAMEX-3: 1) as a calibration and validation facility for CAMEX-3 and 2) as a source of highly detailed, long term measurements of water vapor, aerosols, temperature and other parameters in the sub-tropics during hurricane season. Throughout the experiment, the research aircraft made nu- 
merous calibration/validation overflights of Andros Island allowing ground-based and airbome measurements of water vapor, temperature and winds to be compared. In this paper, we will describe a short segment of the nearly 2 months of measurements acquired at the ground facility: a 4 day sequence of water vapor and cirrus cloud measurements taken between August 21 and 24, 1998 when hurricane Bonnie was in the vicinity of Andros Island. The Scanning Raman Lidar and the other water vapor measuring instruments used in this study will next be briefly described.

\section{The Scanning Raman Lidar}

The Scanning Raman Lidar is a mobile lidar system designed to measure water vapor [17] [32], aerosols [11] [13], cloud liquid water [18], cloud droplet radius and number density [33], cloud base height [4] and upper tropospheric temperature [9]. The SRL detects light backscattered by molecules and aerosols at the laser wavelength as well as Raman backscattered light from water vapor $\left(3657 \mathrm{~cm}^{-1}\right)$, nitrogen $\left(2329 \mathrm{~cm}^{-1}\right)$, and oxygen $\left(1555 \mathrm{~cm}^{-1}\right)$ molecules. The SRL employs two different lasers for its measurements; a XeF excimer laser (351 nm output) for optimized nighttime measurements and a tripled Nd:YAG laser for daytime measurements. The receiving telescope is a $0.76 \mathrm{~m}, \mathrm{~F} / 5.2$, variable field-of-view ( $0.25-2.5$ milliradians) Dall-Kirkham system mounted horizontally on a $3.7 \mathrm{~m}$ optical table. The telescope field-of-view is steered with a large $(1.2 \mathrm{~m} \mathrm{x} 0.8 \mathrm{~m})$, motorized flat mirror which rotates on a horizontal axis and is also mounted on the optical table. The optical table can be slid out the back of the trailer to allow atmospheric profiles to be acquired at any angle in the plane perpendicular to the trailer or continuously scanned from horizon to horizon. Alternatively, the lidar system may be operated completely inside the trailer by directing the output laser beam through one of three windowed openings in the trailer. This allows vertical measurements and measurements at 5-10 degrees above the horizon in either direction to be acquired. It also allows measurements to be made during rainfall. All of the SRL instrumentation, including lasers, large aperture telescope and data acquisition electronics, is housed within a single environmentally controlled mobile trailer which also has separate areas for new experiment development and work space for several experimenters to perform data acquisition and data analysis. More information on the lidar instrument has been published recently [33] and is available at our website http://virl.gsfc nasa.gov/srl/index.htm. The SRL measurements acquired during the passage of Bonnie were made during the nighttime to maximize the signal to noise ratio of the data.

\section{Water vapor measurements}

The additional instruments that measured water vapor at the Andros ground-site will be briefly described here after which the water vapor measurements acquired by these instruments with be discussed.

\subsection{CAMEX-3 ground site water vapor instrumentation}

Total precipitable water vapor (TPW) measurements from several different instruments have been analyzed as a part of this study. These instruments are the SRL, Trimble SSi GPS (U. Wisc.), Vaisala RS-80 radiosonde (U. Wisc.), VIZ hygristor radiosonde (WFF), Cimel sun photometer (NASA/GSFC), GOES satellite, and a combined technique that uses the AERI (U. Wisc.) and GOES. All of the ground-based instruments except the Cimel sun photometer were situated within a $100 \mathrm{~m}$ radius approximately $1 \mathrm{~km}$ from the east coast of Andros Island. The sun photometer was located approximately $1 \mathrm{~km}$ west of the other instruments. The SRL measurements were limited to the nighttime periods while the sun photometer data were limited to daytime. The instruments use different techniques to make their measurements of TPW which can influence the values derived. Those techniques will be briefly summarized here.

The SRL measures a profile of water vapor mixing ratio which, for the purposes of these comparisons here, have been calibrated with respect to 15 radiosondes launched during CAMEX-3. While it is possible to calibrate a Raman lidar absolutely [25], we have found that by carefully selecting radiosonde data [12] and by using a nitrogen filter calibration transfer technique [32], excellent stability in the lidar calibration constant can be maintained. From the first field deployment of the SRL for the Spectral Radiance Experiment in Coffeyville, Kansas in 1991[7] until the CAMEX-3 deployment in 1998, the calibration constant of the SRL determined by comparison with a selection of Vaisala radiosonde data was $7.6 \pm 0.2$. This is the number by which the ratio of water vapor and nitrogen lidar signals must be multiplied to obtain water vapor mixing ratio. This indicates a standard deviation of the calibration constant of approximately $\pm 3 \%$ over almost 7 years. Optical modifications made to the SRL prior to the CAMEX-3 deployment have increased the SRL calibration constant by approximately $15 \%$. This new constant has been used to analyze the data presented here.

The University of Wisconsin AERI instrument measures infrared radiation between approximately 3 and $20 \mathrm{mi}-$ 
crons with less than 1 wavenumber $\left(\mathrm{cm}^{-1}\right)$ resolution using a Fourier transform infrared spectrometer. Radiance spectra acquired every 10 minutes are transformed into vertical temperature and water vapor profiles by inverting the radiative transfer equation [26]. AERI retrievals are limited to an altitude of approximately $3 \mathrm{~km}$. To calculate precipitable water vapor, profiles of water vapor retrieved from GOES satellite using the National Centers for Environmental Prediction (NCEP) algorithms are used above the height of the AERI retrieval. If coincident GOES retrievals are not available, the closest available retrieval is used. The AERI instrument that was deployed to Andros Island is similar to automated ones that have been installed at the Southern Great Plains Site of the Department of Energy's Atmospheric Radiation Measurements Program [29].

VIZ (manufactured by Sippican, Inc) and Vaisala radiosondes were launched from the Andros ground-site during CAMEX-3. The VIZ sensor is a carbon hygristor which uses changes in resistance to determine relative humidity. The Vaisala RS-80 radiosonde uses a thin polymer film whose dielectric properties change as a function of the amount of water vapor. The changes in capacitance created by these changes in dielectric constant are converted into relative humidity.

The Cimel sun photometer is a solar tracking instrument that monitors direct and diffuse solar radiation from which aerosol optical thickness, aerosol size distribution, aerosol phase function and precipitable water vapor are retrieved [23]. The sun photometer was deployed to Andros Island as a part of NASA's AERONET (AErosol RObotic NETwork) effort (http://aeronet.gsfc.nasa.gov:8080/). The goal of this program is primarily to measure aerosol properties. Due to this, the precipitable water vapor measurements are currently believed to have an error of approximately $10 \%$ with a tendency toward a high bias indicated when compared to other instrumentation (Brent Holben, NASA/GSFC, private communication, January, 2000).

The measurement of total precipitable water vapor using ground-based GPS receivers is accomplished by estimating the excess zenith-scaled signal delay caused by the neutral atmosphere [6]. The measurement uses observations from all GPS satellites in view at a fixed site, and requires improved GPS satellite orbits and Earth orientation parameters that are supplied by any one of the International GPS Service Orbit Centers [3]. The signal delays are caused by changes in atmospheric refractivity associated with temperature, pressure, and water vapor along the paths of the signals within a radius of about $11 \mathrm{~km}$ of a site in the mid-latitudes.

During CAMEX-3, two different software packages and improved GPS satellite orbits were used to estimate the zenith tropospheric delays from the data acquired at Andros Island. One estimate was made by the NOAA Forecast Systems Laboratory (FSL) in Boulder, Colorado using GAMIT software developed by the Massachussets Institute of Technology and improved orbits provided by the Scripps Orbit and Permanent Array Center (SOPAC) at the Scripps Institution of Oceanography. Another estimate was made by the GPS Science and Technology (GST) program within the University Consortium for Atmospheric Research (UCAR) in Boulder, using Bernese software developed by the University of Bern and CODE Astronomical Institute orbits from the University of Bem.

The relative calibration of these instruments (or in the case of GPS, the data processing techniques) has been studied for the Bonnie passage period of August 21 - 24. The differences in TPW based on this 4-day sequence of data are shown in figure 1 using the GAMTT-processed GPS precipitable water vapor measurements as a baseline.

The high bias in the Cimel sun photometer of approximately $10 \%$ is consistent with other investigations. It should be noted, though, that this comparison is based just on two days of measurements since the instrument was dismounted during the day on August 22 as a part of hurricane preparations at AUTEC.

Discounting the Cimel, the water vapor instruments' relative calibrations agree to within approximately $+1-4 \%$. The SRL is approximately $1 \%$ wetter than the baseline GAMIT GPS data while the Bernese processed GPS data were approximately $3 \%$ wetter than the baseline. The relative difference between the two methods of GPS processing is consistent with other investigations [21]. It is thought to come from slight differences in data processing strategies. The VIZ and Vaisala radiosondes were within $1-2 \%$ of the baseline with the VIZ showing wetter measurements than the Vaisala. The AERI-GOES retrievals were the driest of the group with average values approximately $4 \%$ lower than the baseline.

The results shown in figure 1 are an indication of the challenges inherent in accurate measurement of atmospheric precipitable water vapor. Based on previous studies of such differences [21] and discounting the Cimel measurements, this level of agreement is actually quite good. While the uncertainties in the water vapor measurements presented here can translate into significant errors in radiative transfer calculations [7], they nonetheless represent significant improvements in the quality of data typically available in the sub-tropics for studying hurricane evolution (e.g. radiosondes alone). 


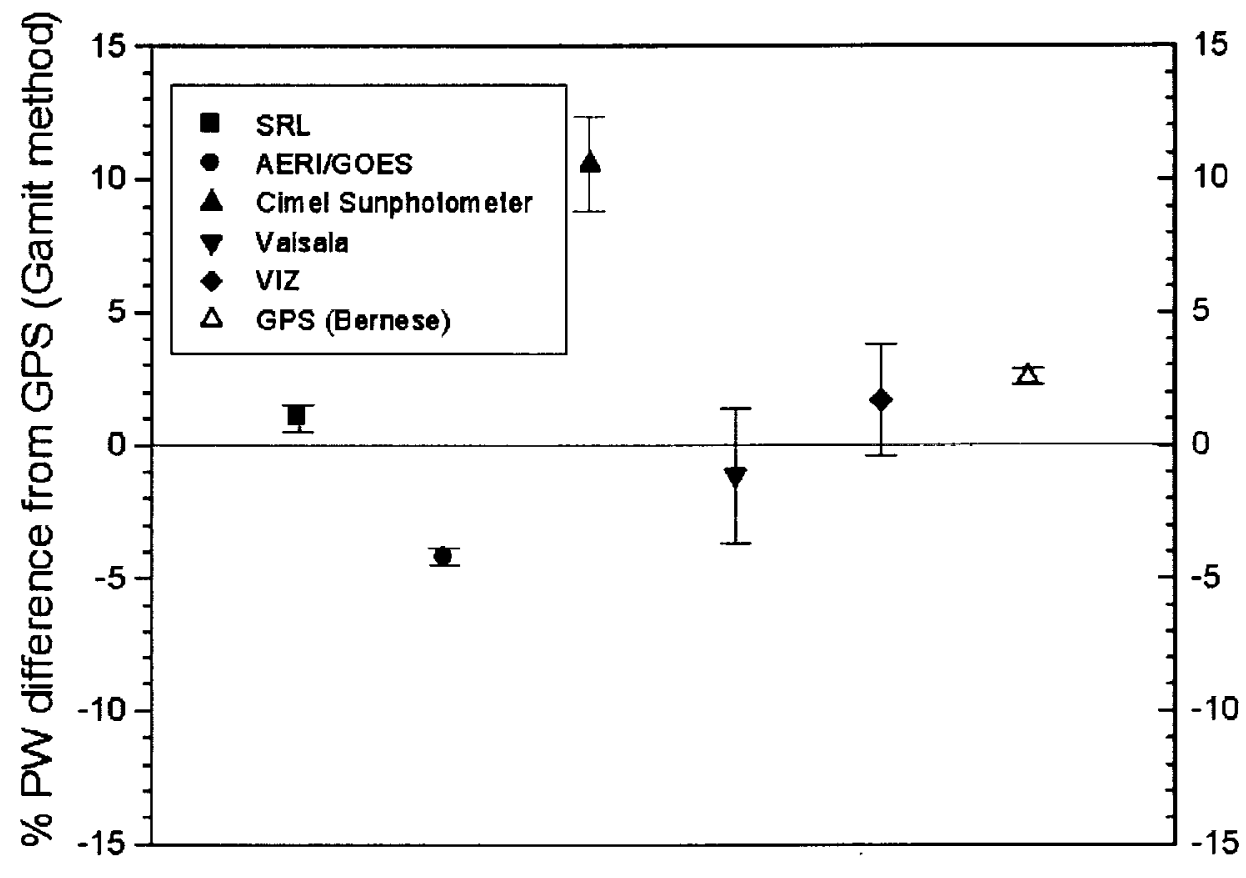

Figure 1: Precipitable water vapor differences among the various sensors stationed at Andros Island Bahamas during the period August 21-24 when Hurricane Bonnie passed nearby. The baseline for the comparison is the GAMIT processed GPS data. 


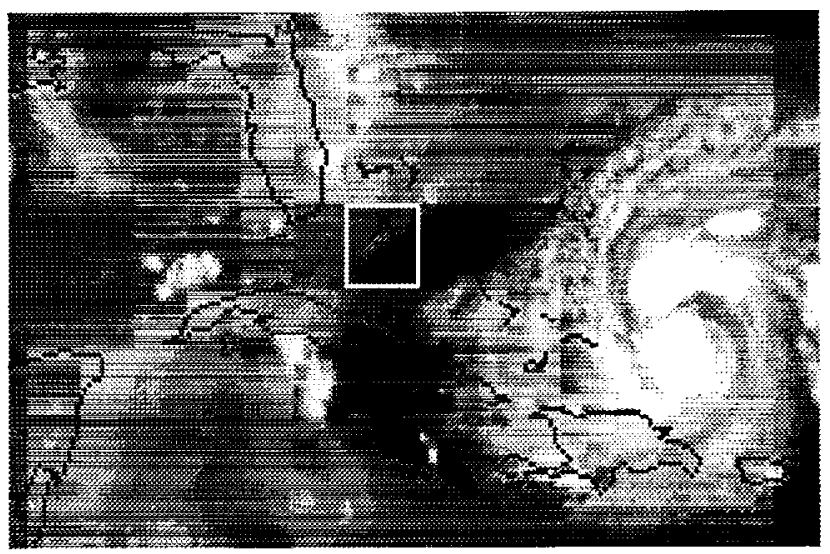

Figure 2: GOES water vapor imagery at 0615 UT on the night of August 22, 1998. Andros Island is indicated by the white box. Also notice the dry subsidence region to the west of the hurricane.

\subsection{Precipitable water vapor measurements during the passage of hurricane Bonnie}

Bonnie became a hurricane on the evening of August 22, 1998 at a point eastward of the Bahamian islands. The GOES water vapor image of Bonnie at 0615 UT is shown in figure 2. Andros Island is indicated by the white box.

Over the next 4 days Bonnie followed a generally northwest track striking the mid-Atlantic coast of the United States on the evening of August 26. The point of closest approach to Andros island was at a distance of approximately 500 kilometers to the east northeast of Andros (24.7 N, $77.8 \mathrm{~W}$ ) on the evening of August 24. Figure 3 shows TPW measurements made by the ground-site instruments during the passage of hurricane Bonnie. As Bonnie approached Andros over the period of August 21 - 22, there was a distinct drying indicated by all instruments during this period. Values of precipitable water vapor changed from approximately $60 \mathrm{~mm}$ on August 21 to approximately $40 \mathrm{~mm}$ on August 22. We believe this drop in TPW to be due to mid-tropospheric subsidence and drying due to the hurricane. During August 22 and most of August 23 the TPW shows a gradual moistening to values of approximately $50 \mathrm{~mm}$ by midday on the 23rd as the subsidence region moved to the west of Andros. Later on August 23 and into August 24, a developing wave disturbance over the gulf of Mexico blocked and reversed the westward movement of the dry region. This resulted in a secondary dry feature in the Andros TPW measurements by 0000 UT on the 24th.

While the general agreement in the TPW measurements reported by the various sensors is quite good, there are interesting discrepancies to mention. The high bias in the Cimel measurements is evident. Differences among the other instruments can be explained at least in part by the fact that the instruments use different techniques to make their measurements of precipitable water vapor which can influence the values derived. For example, in general the SRL and GPS values compare well. However, the SRL data acquired on August 22 are in general lower than either of the GPS retrievals. This may be due to the volume averaging that occurs as a result of using 6-10 more-or-less randomly distributed GPS satellites to measure the zenith-scaled tropospheric signal delay. Satellite imagery tends to support this conclusion as well. The GOES-8 images such as the one shown in figure 2 indicate that for much of the night of August 22 UT, the Andros ground site was at the edge of the dry region. The SRL measurement of TPW was made directly over the ground site while the GPS averaged over a region which included more moist air from surrounding regions.

Another example of a discrepancy between the GPS and the SRL that can be explained by the averaging volume used is seen in the data of August 24. Here a difference of up to $8 \mathrm{~mm}$ is seen between the SRL and GPS TPW values. This can be explained by the presence of localized clouds and showers over the Andros ground site during the night of August 24 which greatly increased the TPW measured by the lidar but which did not significantly affect the GPS measurements.

\subsection{Water vapor evolution as a function of height}

The profile measurements of water vapor made by the SRL can be used to study the height dependence of the changes in precipitable water seen in figure 3 . The SRL water vapor measurements have been divided into layers and integrated 


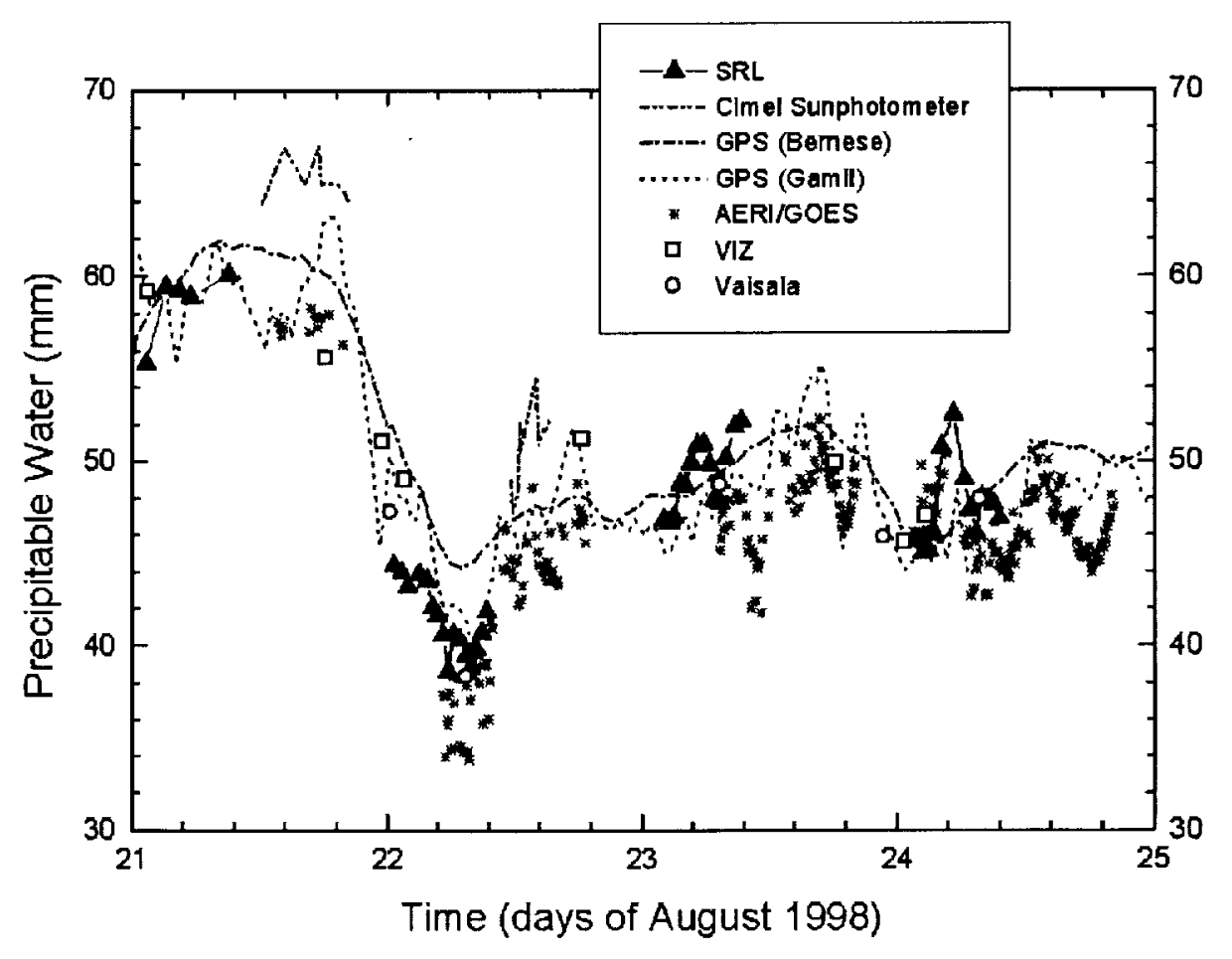

Figure 3: Evolution of precipitable water vapor as measured by Raman lidar, AERI+GOES, GPS (with two different processing algorithms), two types of radiosonde and sun photometer. Two drying periods associated with mid-tropospheric subsidence are evident: early on August 22 and August 24 (UT). All sensors agree in general trends but there are specific differences that can be attributed to measurement techniques. See text for details. 

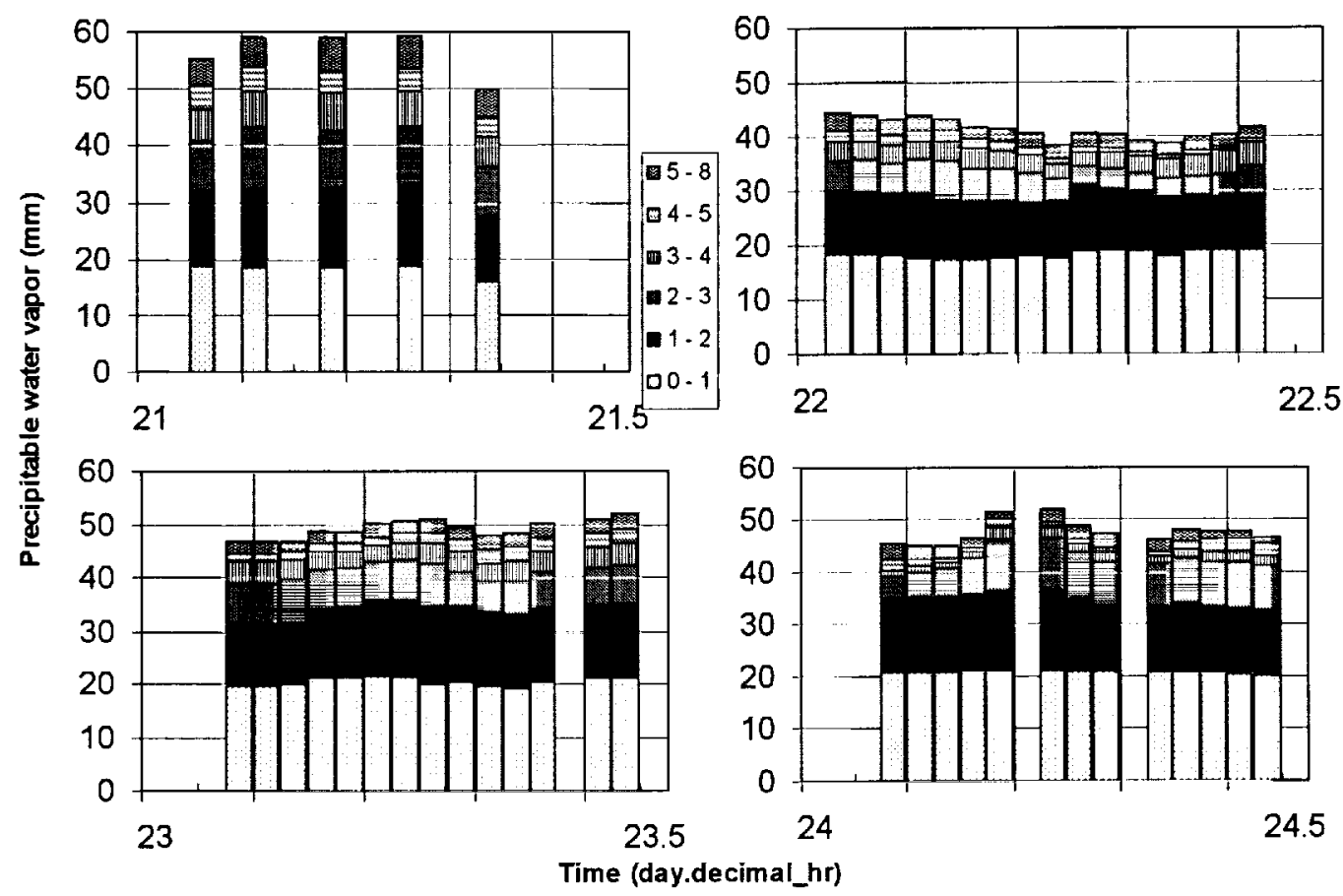

Figure 4: The precipitable water vapor measured by the lidar has been separated into the contributions due to the layers $0-1 \mathrm{~km}, 1-2 \mathrm{~km}, 2-3 \mathrm{~km}, 3-4 \mathrm{~km}, 4-5 \mathrm{~km}$ and $5-8 \mathrm{~km}$. This quantifies the change in column water vapor as a function of height. There was little change in the $0-1 \mathrm{~km}$ layer throughout this 4 day period however significant changes are eveident in other layers.

to yield the precipitable water vapor by layer. These results are shown in figure 4 . The layers used are $0-1 \mathrm{~km}, 1-2 \mathrm{~km}$, $2-3 \mathrm{~km}, 3-4 \mathrm{~km}, 4-5 \mathrm{~km}$ and $5-8 \mathrm{~km}$.

In general, figure 4 shows that the $0-1 \mathrm{~km}$ layer changes very little during the 4-day sequence while precipitable water vapor (PW) contributions from the other layers varies appreciably. This indicates that most of the boundary layer moisture was under local control (evaporation from the sea surface) while middle and upper tropospheric moisture was greatly influenced by the subsidence associated with hurricane Bonnie. For example, between the nights of August 21 and 22, the largest differences in precipitable water vapor occurred in the $2-3 \mathrm{~km}$ layer with values changing from 8 $10 \mathrm{~mm}$ to 4-6 mm. An interesting exception to the depletion of PW at higher altitudes is seen in the 2-3 km layer on the night of August 24 at approximately 0400 UT when rain influenced the local water vapor environment increasing PW values from approximately $5 \mathrm{~mm}$ to approximately $10 \mathrm{~mm}$. This indicates that a significant amount of rain likely evaporated before striking the ground. (There is actually a small enhancement to the $\mathrm{PW}$ measurements during rainfall due to Raman scattering from liquid in the rain droplets [4]. We estimate that this effect increased the precipitable water vapor values in the rainfall by approximately $1-2 \mathrm{~mm}$.)

\section{Cirrus cloud optical depth measurements}

Accurate measurements of sea surface temperature and total precipitable water vapor are needed to improve hurricane track and intensification forecasting. Satellites offer the best chance of providing operational data as input to hurricane models. However, it is well known that the presence of cirrus clouds can pose problems for satellite retrievals. This is because thin cimus clouds, while having small infrared emissivities, can be very cold. Emission from these clouds can cause significant changes in satellite radiances compared to a cloud-free scene. A comparison of Raman lidar cirrus cloud optical depth measurements with retrievals of surface temperature and total precipitable water vapor from GOES-8 will now be performed to study the influence of thin cimus on these satellite retrievals. The same 4-day period 
associated with the passage of hurricane Bonnie will be considered.

The technique for calculating cirrus cloud optical depth using Raman lidar will first be briefly described. Then the magnitude of the influence of multiple scattering on these calculations will be quantified. The optical depth values obtained in the UV will then be translated to the IR. A simple radiative transfer model will then be used to quantify the anticipated radiance seen by GOES satellite under varying cirrus conditions. Comparisons of the predictions of this model with values derived using the split window technique [27] will then be presented. Lidar measured TPW will also be compared with TPW retrieved from GOES data.

\subsection{Optical depth calculations using Raman lidar}

The optical depth calculation from Raman lidar is based on the molecular nitrogen signal which shows enhanced attenuation due to the presence of a cirrus cloud. The amount of this attenuation can be converted to optical depth once the atmospheric density is known. The equation which yields optical depth is obtained by integrating the equation for aerosol extinction [1] and can be written as

$$
\int_{r_{1}}^{r_{2}}\left[\alpha\left(\lambda_{L}, r\right)+\alpha\left(\lambda_{N}, r\right)\right] d r=\ln \left(\frac{r_{1}^{2} N_{N}\left(r_{2}\right) P\left(\lambda_{N}, r_{1}\right)}{r_{2}^{2} N_{N}\left(r_{1}\right) P\left(\lambda_{N}, r_{2}\right)}\right)-\int_{r_{1}}^{r_{2}}\left[\alpha_{m o l}\left(\lambda_{L}, r\right)-\alpha_{m o l}\left(\lambda_{N}, r\right)\right] d r
$$

where $r_{1}$ is the base of the cloud, $r_{2}$ is the top of the cloud, $\lambda_{L}$ is the laser wavelength (351.1 nm), $\lambda_{N}$ is the wavelength of the Raman nitrogen signal $(382.4 \mathrm{~nm}), \alpha\left(\lambda_{x}, r\right)$ is the cloud extinction coefficient as a function of wavelength and range, $N_{N}(r)$ is the number density of atmospheric nitrogen (using the full atmospheric number density is equivalent) as a function of range, $P\left(\lambda_{N}, r\right)$ is the lidar Raman nitrogen signal and $\alpha_{m o l}\left(\lambda_{x}, r\right)$ is the extinction coefficient due to molecular scattering obtained from radiosonde data. Lidar measurements in cloud-clear regions indicated that aerosols did not contribute to the optical depths measured at cirnus altitudes. Also, at these wavelengths, gaseous absorption is negligible and need not be included.

Equation 1 yields the two-way optical depth which is the fundamental quantity measured by the Raman lidar. To convert this to a one-way optical depth, the wavelength scaling of cloud particle scattering must be considered. Assuming an Angstrom coefficient of $k=0$ in the following equation

$$
\frac{\alpha\left(\lambda_{L}, r\right)}{\alpha\left(\lambda_{N}, r\right)}=\left(\frac{\lambda_{N}}{\lambda_{L}}\right)^{k}
$$

which is valid for cirrus particles that are typically very large with respect to the laser wavelength of $351 \mathrm{~nm}$, the one-way optical depth at $351 \mathrm{~nm}$ is just one half of the two way optical depth shown in equation 1 .

However, equation 1 does not account for any multiple scattering that may occur in the cloud. The influence of multiple scattering is mainly due to one or more forward scattering events accompanied by a single backscatter event [8]. Multiple scattering is much more likely when large particles are encountered because of the intense forward scattering diffraction peak associated with these particles. This forward scattered component is added back into the beam and decreases the apparent attenuation of the beam. Thus the influence of multiple scattering is to decrease the optical depth measured by lidar compared to the actual value. Lidar parameters such as the telescope field of view (2 milliradians for the SRL) and the laser divergence (1 milliradian) also influence the multiple scattering component of the signal. The influence of multiple scattering on the Raman lidar measurements of optical depth during the hurricane Bonnie passage period of August $21-24$ will now be studied.

\subsection{Multiple scattering calculations}

In order to estimate the magnitude of multiple scattering in these cirrus cloud measurements, the formulation developed by Eloranta [8] has been used. The ratio of double and triple scattering to single scattering can be expressed as

$$
\begin{aligned}
\frac{P_{2}(R)}{P_{1}(R)}= & \frac{\mathcal{P}_{2}(\pi, R)}{\mathcal{P}_{1}(\pi, R)}\left[1-\exp \left(-\frac{\rho_{t}^{2}}{\rho_{l}^{2}}\right)\right]\left\{\tau-\int_{0}^{d} \beta_{s}\left(x_{1}\right) \exp \left(-\frac{\rho_{t}^{2} R^{2}}{x_{1}^{2} \Theta_{s}^{2}\left(x_{1}\right)+\rho_{l}^{2} R^{2}}\right) d x_{1}\right\} \\
\frac{P_{3}(R)}{P_{1}(R)}= & \frac{\mathcal{P}_{3}(\pi, R)}{\mathcal{P}_{1}(\pi, R)}\left[1-\exp \left(-\frac{\rho_{t}^{2}}{\rho_{l}^{2}}\right)\right] \\
& \times\left\{\tau-\int_{0}^{d} \beta_{s}\left(x_{1}\right) \int_{x_{1}}^{d} \beta_{s}\left(x_{2}\right) \exp \left(-\frac{\rho_{t}^{2} R^{2}}{x_{1}^{2} \Theta_{s}^{2}\left(x_{1}\right)+x_{2}^{2} \Theta_{s}^{2}\left(x_{2}\right)+\rho_{l}^{2} R^{2}}\right) d x_{2} d x_{1}\right\}
\end{aligned}
$$


where

$$
\tau=\int_{0}^{d} \beta_{s}(x) d x
$$

is the optical depth. In these equations, $P_{n}$ is the signal intensity due to $n t h$ order scattering, $\mathcal{P}_{n}(\pi, R) / \mathcal{P}_{1}(\pi, R)$ is the ratio of phase functions in the backscatter direction encountered by an $n t h$ - order scattered photon and a singly scattered photon. For Raman backscatter, this ratio is equal to 1.0 due to the broad nature of the molecular phase function near the backscatter direction. The telescope half angle field of view is $\rho_{t}, \rho_{l}$ is the laser half angle divergence, $d$ is the depth of penetration into the cloud determined by the location of the backscattering event, $\beta_{s}$ is the extinction coefficient, and $\Theta_{s}$ is the 1/e diffraction peak angular half-width. These equations have been slightly reformulated from the published version in a manner that allows for more efficient numerical calculation (Edwin Eloranta, University of Wisconsin, private communication, January, 2000). An estimate of the diffraction peak angular width for cirrus particles can be made by determining the first zero of the scattering amplitude for a circular disk which is given by [2]

$$
S(\theta)=x^{2} \frac{1+\cos (\theta)}{2} \frac{J_{1}(x \sin \theta)}{x \sin \theta}
$$

Here $\theta$ is the scattering angle measured with respect to the forward direction, $x$ is the size parameter of the spherical particle defined as the circumference divided by the radius and $J_{1}$ is the first Bessel function of the first kind.

Examination of equations 2 and 3 indicates that in order to calculate the influence of multiple scattering on real lidar measurements, one needs to know the true optical depth and the angular width of the diffraction peak which is a function of particle size. These quantities are not known in advance so in order to estimate the influence of multiple scattering on Raman lidar measurements of cirrus optical depth, results from in-situ measurements and modeling studies were used.

In-situ measurements of cirrus clouds indicate that particles can range in size from perhaps 10 microns at the tops of cold clouds to several hundred microns in warm cirmus clouds and in fall streaks [20]. For the cold cirnus clouds which are studied here, effective radii in the range of 10-20 microns are typical [36]. Recent work [15] has shown that, for many radiative transfer calculations including those of multiple scattering, using a collection of equal radius spheres to represent a single non-spherical ice particle can yield Mie calculations which closely approximate the results of exact ray trace solution for ice crystals. The sphere radius and the number of spheres in the collection are chosen such that the ratio of volume to area of the collection equals that of the single ice particle. Thus, to use equation 4 to calculate the diffraction peak angular width of an ice particle, it is the radius associated with the equal volume/area collection of spheres that is appropriate. Although we expect much smaller particles in the cirrus clouds studied here, we investigated multiple scattering due to a range of particle sizes up to 160 microns in radius as a part of this investigation.

Modeling studies indicate that realistic values of the cirrus extinction to backscatter ratio cover a range of approximately 5-20 [1] [28]. For a given extinction to backscatter ratio, the corresponding true optical depth can be found by multiplying extinction to backscatter by the Raman lidar aerosol backscatter coefficient and integrating through the cloud. This can be done since the backscattering coefficient has very little multiple scattering influence. (In measurements that involve a ratio of Raman signals, the multiple scattering cancels completely while for the ratio of particle to molecular scattering used to calculate the cirrus cloud backscatter coefficient [33], the influence of multiple scattering is much less than $1 \%[30]$ ).

As a typical example of multiple scattering in Scanning Raman Lidar measurements in a cirrus cloud, the combination of extinction to backscatter ratio of 5 and mean particle diameter of 40 microns was used in figure 5 . This figure also shows the cirrus cloud backscatter coefficient as a function of range measured on the night of August 23, 1998. Two portions of the cloud are shown: one that is optically thin (measured optical depth $\simeq 0.1$ ) on the left and on the right one that is among the most optically thick measured on August $23(\mathrm{OD} \simeq 0.7)$. Also plotted are the ratios of second and third order multiple scattering to single scattering for the Raman nitrogen measurement. The magnitude of third order multiple scattering was less than $5 \%$ of the second order scattering in both of these cases. The total multiple scattering shown in figure 5 (second + third order) corresponds to differences between measured and true optical depths of approximately $0.004(4 \%)$ and $0.04(\sim 6 \%)$ for the thin and thick cases, respectively.

For the parameters of the SRL instrument of 1 milliradian laser divergence and 2 milliradian field of view, the multiple scattering influence for both double and triple scattering did not increase for particles with radii larger than 
approximately 75 microns independent of the extinction to backscatter ratio used. For these large particle test cases, double and triple scattering resulted in errors in optical depth of approximately $40 \%$ and $10 \%$, respectively.

For large particle scattering, the forward scattered diffraction peak accounts for $50 \%$ of the total scattered light. For particles larger than 75 micron radius, double and triple scattering added up to this maximum value indicating that the contribution of higher scattering orders was insignificant and that essentially all of the forward scattered light remains in the field of view of the telescope. Thus, triple scattering contributed at most $25 \%$ of the total multiply scattered signal.

By examining various test cases covering a range of particle radii (5-160 micron) and extinction to backscatter ratios (5-20) it was estimated that triple scattering contributes less than $10 \%$ of the total multiple scattering signal in these cirnus clouds. Higher scattering orders contribute negligibly. These results agree with previous studies [30] which also concluded that second order scattering dominates the multiply scattered signal in cirrus clouds

For some combinations of small particles, small extinction to backscatter ratios (and thus small optical depths), there was very little enhancement of the signal due to multiple scattering. This implies that, for thin cirnus clouds comprised of small particles, multiple scattering should not influence the optical depth measurement significantly. This disagrees with the results of an earlier study [30] which indicated that the optical depth of a thin cirrus cloud (OD $\lesssim 0.1)$ measured by a Raman lidar can be expected to be approximately one-half of the actual value due to multiple scattering. The results here indicate that this amount of enror at cloud base would occur only if large particles are found at the base of the cloud. Thus, it is not true in general that Raman lidar measurements of small optical depths have large errors.

Based on the multiple scattering studies performed here and assuming a distribution of particle sizes typical of cold cirrus clouds, we estimate that these Raman lidar measurements of optical depth are from a few percent up to $20 \%$ less than the actual cirrus optical depth.

\subsection{Hurricane Bonnie cirrus clouds}

Raman lidar measurements of cirrus cloud optical depth (at $351 \mathrm{~nm}$ ) acquired at the Andros Island ground site for the nights of August $21-24$ are presented in figure 6 . The values have been increased by $10 \%$ over the lidar measured values to estimate the influence of multiple scattering. The enror in optical depth due to this multiple scattering correction is approximately $\pm 10 \%$. A 10 -minute running average of lidar data has been used for these calculations. The error bars plotted indicate the uncertainty of the measurement according to Poisson statistics.

The lidar data were also used to calculate cirmus altitude and geometrical thickness. These measurements indicate cirrus base height ranged from a minimum of approximately $9 \mathrm{~km}$ at 0530 UT on August 21 when the cloud thickness was approximately $5 \mathrm{~km}$ (optical depth approximately 1.4) to approximately $16 \mathrm{~km}$ at 0900 UT on August 24 when the thickness was less than $1 \mathrm{~km}$ (optical depth less than approximately 0.01 ). There were times when lidar optical depth measurements were not possible. These were due to rain (after 0600 on August 21), system filter changes (0200-0245 on August 21 and 0200-0330 on August 22), low clouds (0500 - 0600 on August 24). The other period of no data occurs after 0600 UT on August 22 and indicates that no cirrus were detected by the lidar during this time.

Because of the range of optical depths covered, the measurements of August 23 provided a corvenient dataset to test the sensitivity of satellite retrievals to the presence of cirrus clouds. On this night the measured optical depth at $351 \mathrm{~nm}$ ranged from a minimum of much approximately 0.01 to a maximum of approximately 0.7 . (It is interesting to note that the optical depth limit for visual detection of cirrus during the daytime has been determined to be $\lesssim 0.03$ [24]). The lidar cloud backscatter coefficient image is shown in figure 7. Here the backscatter coefficient is shown using a log scale with values ranging from approximately $3 \times 10^{-4}$ and $3 \times 10^{-2}\left(\mathrm{~km}^{-1} \mathrm{sr}^{-1}\right)$.

In order to estimate the radiative effects of these cirrus clouds, a simple radiative transfer model which accounts for surface emissivity, surface temperature, cloud emissivity and cloud temperature was used. The model equation is

$$
R_{s a t}=\left(1-\varepsilon_{c}\right) \varepsilon_{s} \beta\left(\lambda_{s a t}, T_{s}\right)+\varepsilon_{c} \beta\left(\lambda_{s a t}, \bar{T}_{c}\right)
$$

where $R_{s a t}$ is the predicted satellite irradiance ( $\mathrm{W} \mathrm{m}^{-2} \mathrm{sr}^{-1} \mu \mathrm{m}^{-1}$ ), $\varepsilon_{c}$ is the cirrus cloud emissivity calculated from $\varepsilon_{c}=\left(1-e^{-\tau_{c}}\right)$ where $\tau_{c}$ is the cirrus infrared optical depth, $\varepsilon_{s}$ is the surface emissivity, $\beta(\lambda, T)$ is the Planck function, $\lambda_{s a t}$ is the wavelength of the satellite instrument channel, $T_{s}$ is the surface radiating temperature and $\bar{T}_{c}$ is the mean cirrus cloud radiating temperature. The first term in equation 5 is the surface contribution to the satellite irradiance and the second term is the contribution due to the cirms cloud. The satellite effective brightness temperature $T_{s a t}$ is then obtained numerically from the Planck function for the value of $R_{s a t}$. Averaging over the GOES 11 and 

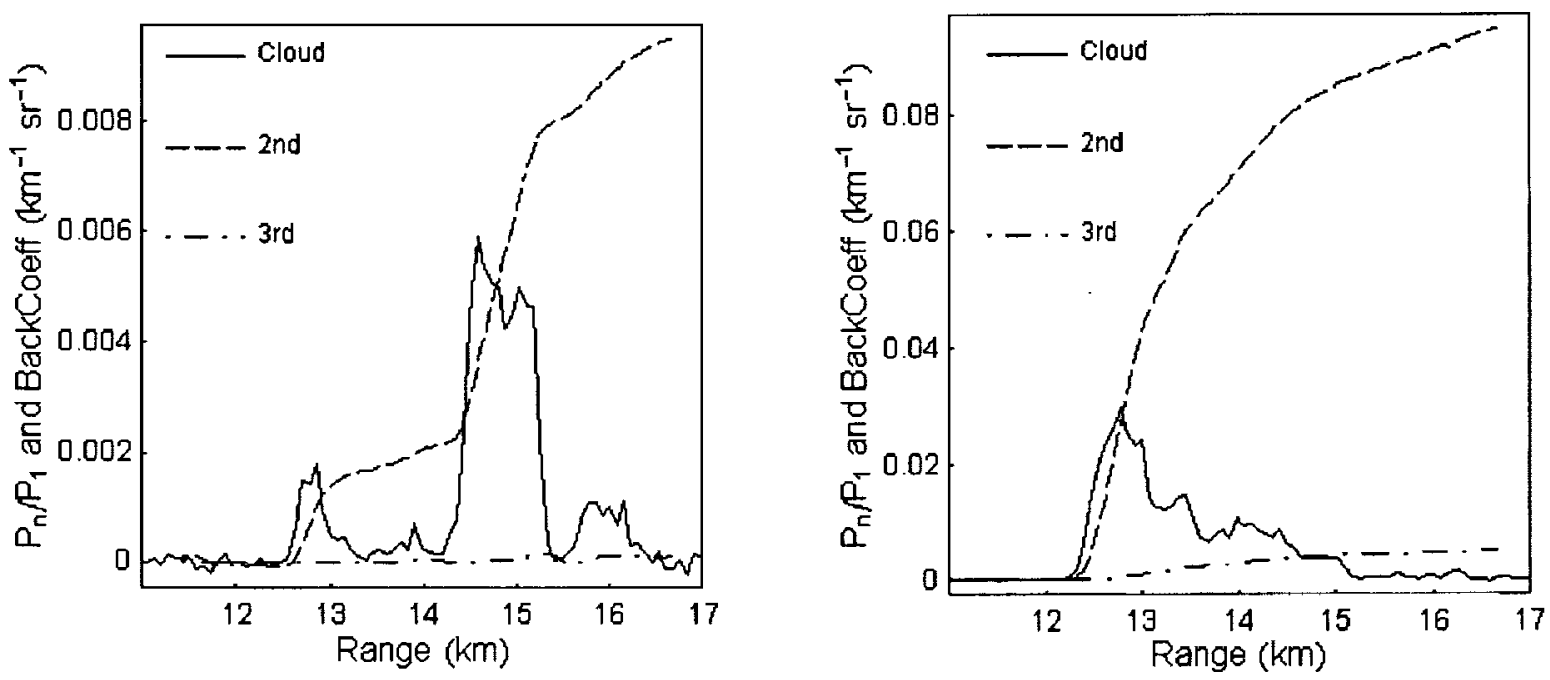

Figure 5: Second and third order multiple scattering calculated for two portions of the cirrus cloud measured on the night of August 23. Also shown is the cloud backscatter coefficient. On the left is shown the results of these calculations for an optically thin segment of cirrus with $O D \simeq 0.1$ for a particle diameter of 40 microns and an extinction to backscatter ratio of 5 . On the right is shown the results using the same multiple scattering parameters for the optically thickest part of the cimus during the night with $O D \simeq 0.7$. Note the change in scale between the left and right figures. Based on studies such as this, it was concluded that 1) double scattering is the dominant source of multiple scattering in cirrus clouds and 2) the errors due to multiple scattering in these lidar measurements of cirnus cloud optical depth range from a few percent up to $20 \%$. (Note the scale change between the two figures) 

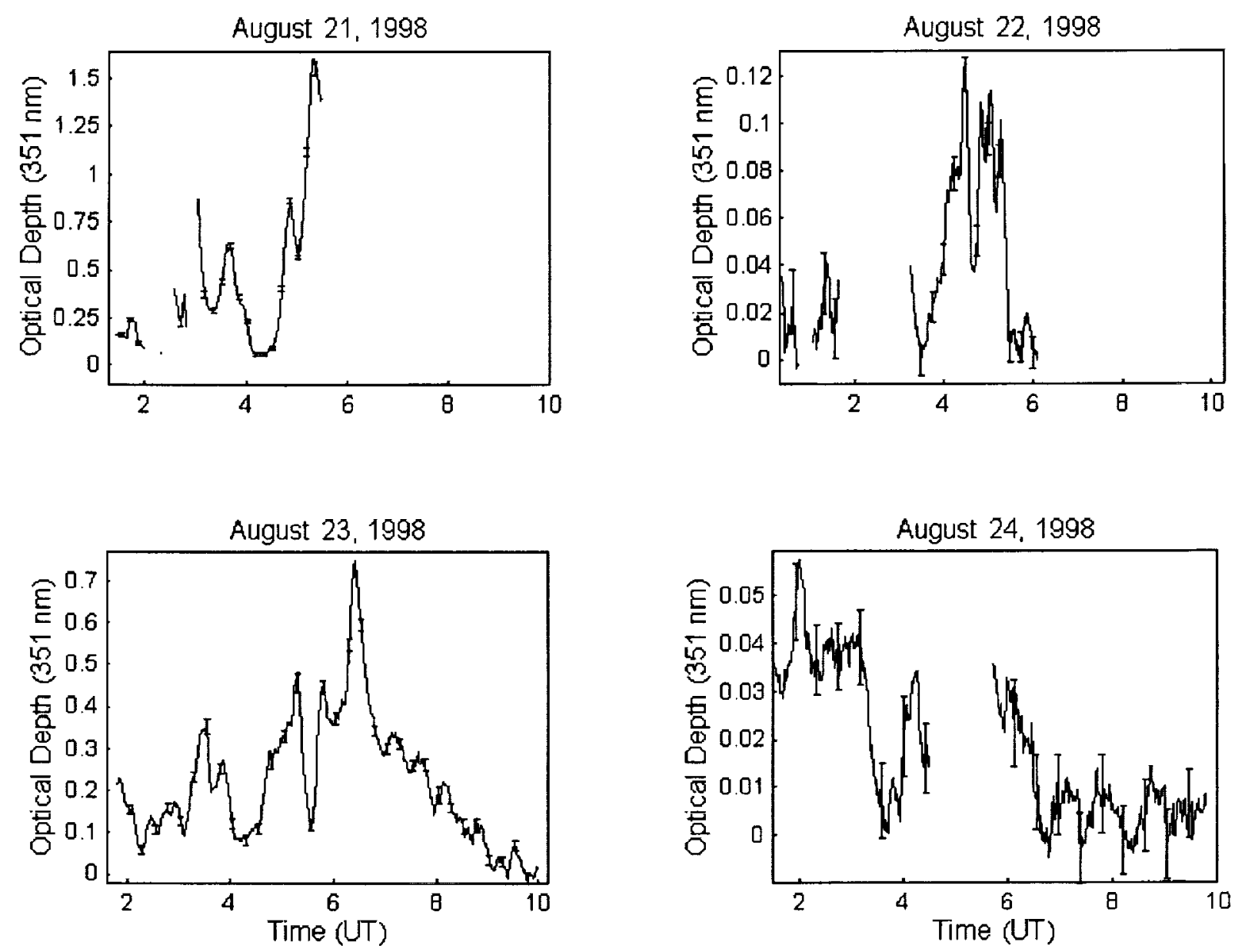

Figure 6: Four night sequence of cirrus optical depth as measured by the Scanning Raman Lidar. Values reported are for $351 \mathrm{~nm}$ and have been adjusted for the estimated effects of multiple scattering. The error bars reported are those calculated from Poisson statistics based on the strength of the lidar signal. Note that the optical depth scale changes for each of the plots. 
Cirrus Backscatter Coefficient-August 23, 1998

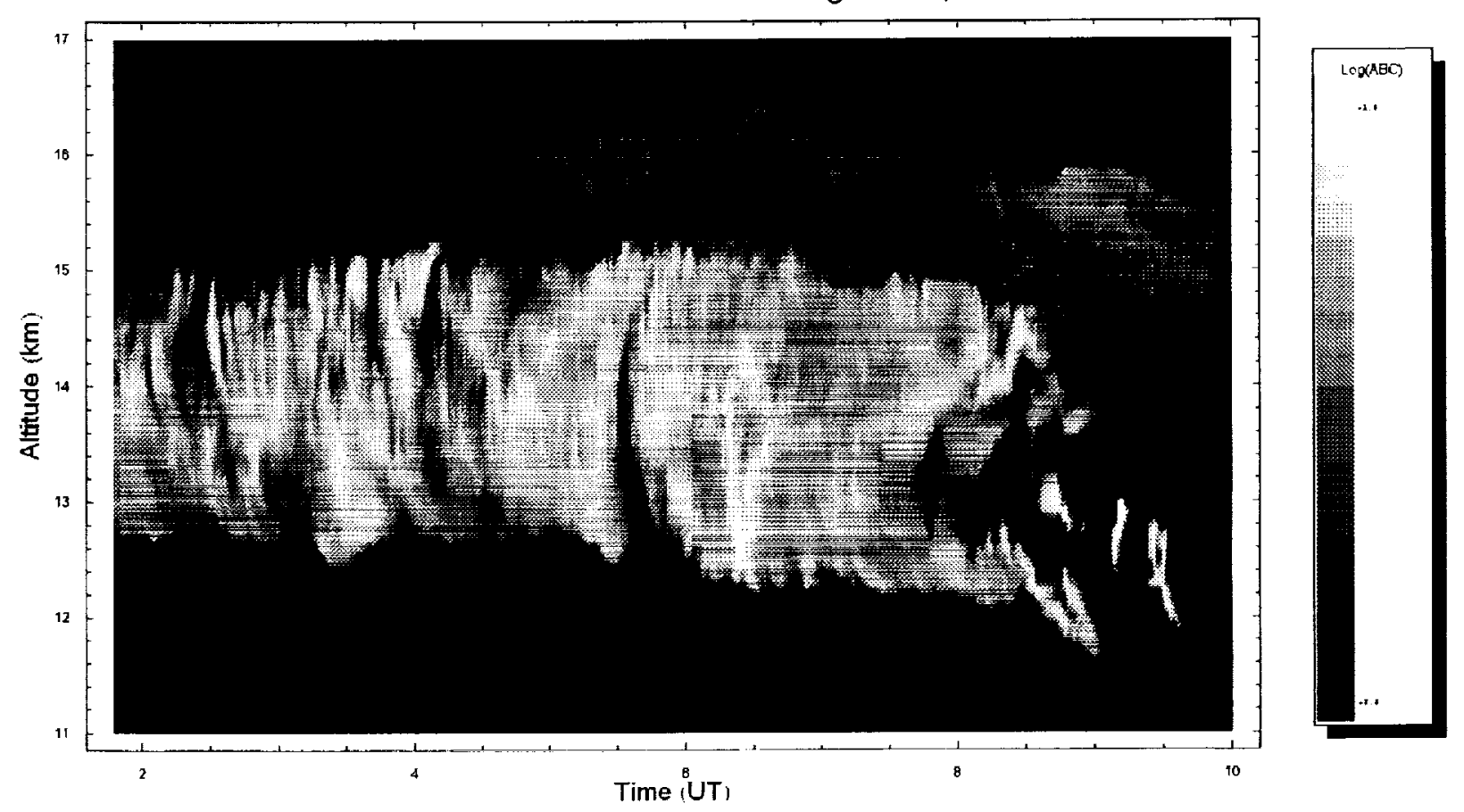

Figure 7: Scanning Raman Lidar measurements of cirrus cloud backscatter coefficient on the night of August 23, 1998 at Andros Island. 
12 micron channel filter widths is required since the index of refraction of ice varies significantly in this region of the spectrum [31].

The purpose of this equation is not to yield highly accurate values of satellite radiance but rather to study the influence of varying cirrus optical depths on those radiances. Toward that end, the values used in equation 5 were: $\varepsilon_{s}=0.95, T_{s}=302 \mathrm{~K}$ obtained from GOES during a cloud-clear period, $\bar{T}_{c}=214 \mathrm{~K}$ obtained from radiosonde measurement.

In order to use the lidar measured optical depths for infrared radiative transfer calculations, the optical depths must be translated to the IR. The ratio of visible $(532 \mathrm{~nm}$ from a Nd:YAG laser) to infrared cirrus optical depth has been shown to vary between approximately 1.6 and 2.4 [35] [5]. This ratio depends on particle size and, due to the changing values of the index of refraction of ice, the exact spectral locations that are being compared. These studies have indicated that the values for 11 microns typically are larger than for 12 microns.

To study the ratio of UV/IR cirrus optical depths, the same approach described in Wylie et. al. [35] was used where the cirnus IR optical depth $\tau_{c}$ can be approximated using the following equations.

$$
\begin{aligned}
& \tau_{c}=-\ln \left(1-\varepsilon_{c}\right) \\
& \varepsilon_{c}=\frac{T_{c l r}^{4}-T_{s a t}^{4}}{T_{c l r}^{4}-\bar{T}_{c}^{4}}
\end{aligned}
$$

In these equations, $T_{c l r}$ is the blackbody brightness temperature for a clear GOES pixel. Using the GOES brightness temperatures during the night of August 23 which are shown later in figure 9, the ratio of UV (351 nm) and IR (at the GOES 11 and 12 micron channel positions) cirnus cloud optical depth was evaluated using equations 6 and is shown in figure 8.

The mean values for the ratio of optical depths shown in figure 8 are $1.6 \pm 0.6$ at 11 microns and $1.4 \pm 0.5$, at 12 microns. While there is significant uncertainty in these values due to the small sample size, these results point to the conclusions that 1 ) the 11 micron ratio is larger than the 12 micron ratio which is consistent with the VIS/IR ratio studies mentioned earlier and 2) these UV/RR values are approximately $20 \%$ lower than the VIS/IR ratios. Both of these results can be related to the size of the ice particles in the cloud.

Depending on the size of the crystal, ice particle extinction efficiency can change quite significantly between 11 and 12 microns due to the large changes in index of refraction of ice in this spectral region [36]. When small ice crystals are involved (10-20 microns in radius), the extinction efficiency at 12 microns is significantly larger than at 11 microns. This effect has been observed in thin cirnus clouds using Nimbus-4 data [19]. Therefore, the results of figure 8 which show an 11 micron UV/RR optical depth ratio which is larger than the 12 micron ratio can be an indication of small particle sizes in these cold clouds $(-55 \mathrm{C}$ to $-70 \mathrm{C})$. For very large diameter crystals such as would be expected in cirrus uncinus, the extinction efficiencies at 11 and 12 microns should be quite similar so that one would expect the two curves in figure 8 to overlay each other. It should be mentioned, however, that since smaller crystals are expected at the tops of the clouds, the conclusion of small ice crystals based on the IR data could be influenced by a top-of-cloud bias in the $\mathbb{R}$ radiances. Because of this possible bias, the location of the instrument making the $\mathrm{R}$ measurement of optical depth, whether on the ground [5] or from satellite [35], must be considered in the analysis. With this in mind, the difference between the UV/RR optical depths ratios determined here and the VIS/IR optical depth ratios determined before [5] [35] are likely related to both the particle sizes in the cirrus clouds that were studied and to the techniques used to derive the IR optical depths. We will study this ratio with more GOES comparisons in the future, but, for this study, we have used the values of 1.6 and 1.4 as the scaling factors to adjust the lidar measured optical depths to those appropriate for the GOES 11 and 12 micron channel positions.

Figure 9 shows the brightness temperatures calculated from equation 5 and the Planck function using the parameters described above for both the 11 and 12 micron GOES channels (long dash and dot-dot-dash lines, respectively). Also plotted are the actual GOES 11 and 12 micron channel brightness temperatures (closed boxes and triangles) and the retrieved skin surface temperature using the split-window physical retrieval technique [27] (open triangles). No cloud screening was performed in these retrievals. Therefore, the GOES brightness temperatures and the subsequent retrievals have the effects of cloud-contamination implicitly in them. This is done for the GOES pixel that contains the lidar location (on the left in the figure) and for the adjacent pixel $10 \mathrm{~km}$ to the east of this location (on the right) and thus completely over the ocean. (The cirrus optical depth is plotted for comparison in figure 10).

There are several points that can be made from this figure. Despite the sampling issues relating to the comparison of 10-minute averages of lidar data and $10 \mathrm{~km}$ satellite pixels, these simple model calculations capture the main features 


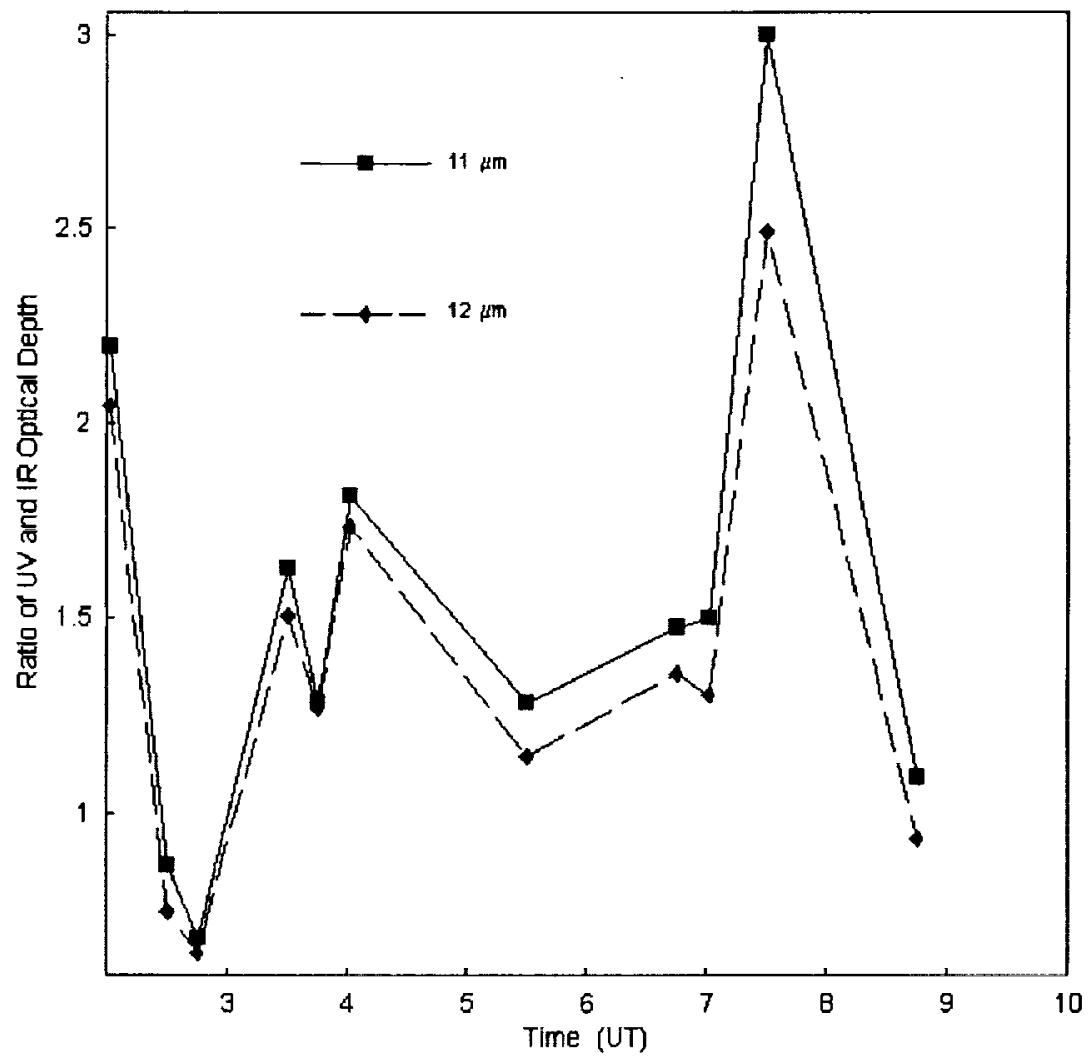

Figure 8: The ratio of optical depth at the laser wavelength of $351 \mathrm{~nm}$ and the GOES 11 and 12 micron channel positions determined using the technique of Wylie et. al. 

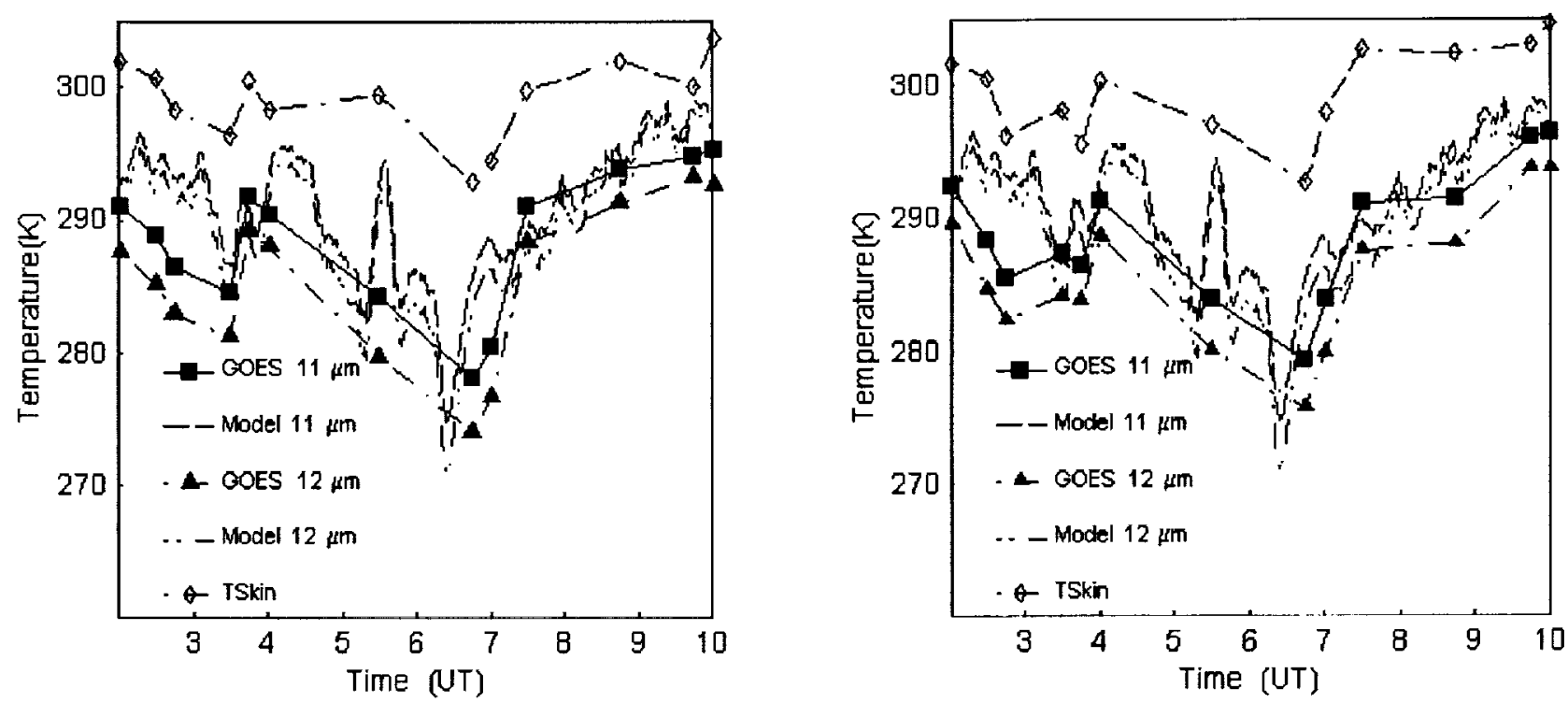

Figure 9: Comparison of GOES 11 and 12 micron channel brightness temperatures and model calculations for the satellite pixel directly over the lidar site (left) and the pixel $10 \mathrm{~km}$ to the east of the site (right). Also plotted are the retrieved skin surface temperatures using the split-window technique. The model assumes constant surface and cloud temperatures. The two pixels show generally good correlation of features. It is evident that even very thin cirrus clouds influence satellite radiances. For comparison, the cimus optical depth values are in the next figure. 
observed in the satellite brightness temperatures. Also, the pixels over land (left) and over water (right) show good general agreement indicating that the constant surface temperature assumption in the model retrievals is reasonable. That being the case, the third point is that, for both of these pixels, the changing cimus cloud optical depth is the dominant factor causing fluctuations in the satellite brightness temperatures. This influence lasts until approximately 0900 UT as indicated by the general slope in the model predictions toward higher brightness temperatures. Taking $0900 \mathrm{UT}$ as an estimate of the first time during the measurement period when the satellite brightness temperatures were uninfluenced by the presence of cirrus, the $\mathrm{R}$ optical depth threshold above which the presence of cirrus significantly influences GOES satellite brightness temperatures is estimated to be 0.02 . It is again interesting to note the 0.03 optical depth limit for visual detection. It is reasonable to expect that a cimus cloud that can not be seen by the naked eye might also have little radiative impact on satellite measurements.

This result can be compared to those of Wylie and Menzel [34] in their study of VAS data in which they concluded that $50 \%$ of the clouds with IR optical depths of 0.1 or less went undetected. If this statistic is representative of the current state of cloud detection algorithms, it seems evident that the probability of undetected cirrus significantly influencing satellite data is high.

The corresponding precipitable water retrievals using the split-window technique are shown in figure 10 . In this figure, the lidar-derived precipitable water and the cirnus optical depth measurements (adjusted to the IR) are also plotted. The lidar measurements indicate that the TPW changed relatively little during the measurement period. All significant variation in the retrieved TPW from GOES is attributed to the influence of cirrus.

It is clear from figure 10 that the cirnus-induced errors in the retrieval of TPW are larger than and in opposite direction to those in skin temperature shown in figure 9 . Increases in cirnus optical depth depress the retrieved surface temperature and elevate the retrieved TPW. A simple explanation for this effect can be obtained by considering the adjustments in the derived values of surface temperature or precipitable water required to account for the change in radiance due to the presence of cirrus. Due to the $\mathrm{T}^{4}$ dependence of blackbody radiant energy, small reductions in retrieved surface temperature can explain the reduced brightness temperatures of a cirrus cloud contaminated scene. However, large increases in precipitable water are required to bring about comparable reductions in brightness temperatures since the precipitable water is concentrated near the surface and is characterized by a radiating temperature that contrasts with the surface temperature much less than do cirrus cloud temperatures.

\section{Summary and Conclusions}

The NASA/GSFC Scanning Raman Lidar (SRL) was stationed at Andros Island, Bahamas during August - September, 1998 as a part of the third Convection and Moisture Experiment (CAMEX-3) hurricane study program. Lidar measurements of water vapor and cirrus clouds have been compared with various other sensors during the four day period of August 21 - 24 when hurricane Bonnie passed near the island. The relative calibration of the instruments was compared. The Cimel sun photometer was found to exhibit a wet bias of approximately $10 \%$ compared with the baseline measurement of precipitable water from the GPS using GAMIT processing. Differences between the GAMTT and Bemese processing of approximately $3 \%$ with the Bemese technique producing wetter results are attributed to minor differences in data processing strategies.

The evolution of the precipitable water vapor during this period was studied revealing two drying episodes related to hurricane-induced mid-tropospheric subsidence. Using the SRL profiling capability, the evolution of precipitable water was studied by layers indicating that the predominant changes in column water occurred above $1 \mathrm{~km}$. There also was evidence of mid-tropospheric humidification due to rainfall on August 24.

The evolution of cirrus cloud geometry and optical depth was studied as well. The influence of multiple scattering on the lidar measurements was first studied with the conclusion that the lidar measurements are from $0-20 \%$ less than the real optical depth. These multiple scattering studies indicated that, for low optical depth clouds containing small particles, the errors due to multiple scattering can be insignificant. After converting the UV optical depths to IR optical depths based on a comparison of SRL optical depth and GOES brightness temperatures, the predictions of satellite brightness temperatures from a simple radiative transfer model were compared with actual GOES brightness temperatures. These predictions indicated that satellite radiances are noticeably affected for cirrus optical depths above approximately 0.02 . Larger enrors were induced in the retrieved precipitable water than in the retrieved skin temperatures.

An important conclusion of this effort is that satellite retrieval algorithms need to be able to detect the presence of cirrus clouds with optical depths as small as 0.02 in order to avoid significant influences on satellite radiances and thus potential errors in retrievals. Improved satellite measurement strategies such as the $1.375 \mu \mathrm{m}$ cirmus channel of 

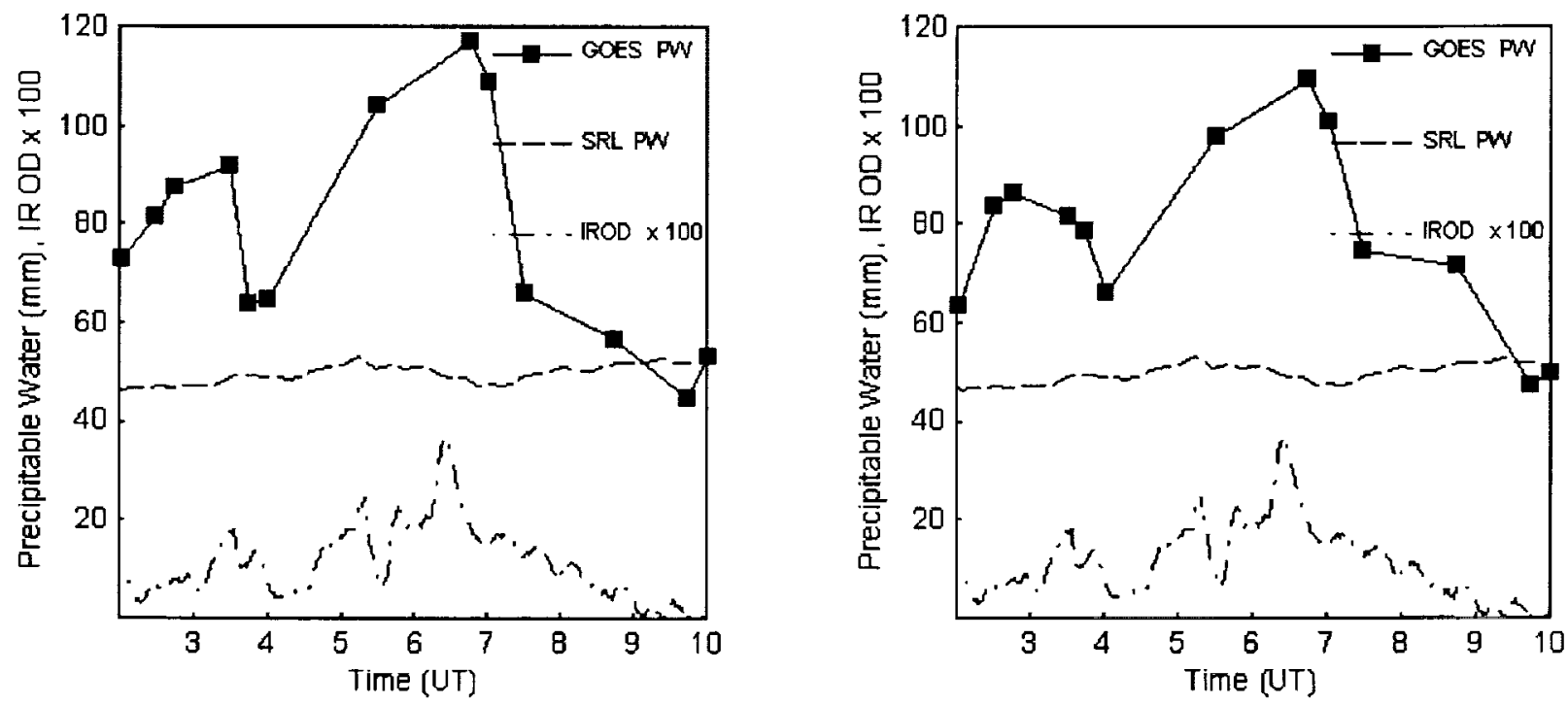

Figure 10: Retrieved precipitable water from GOES for the satellite pixel directly over the lidar site (left) and the pixel $10 \mathrm{~km}$ to the east of the site. Also plotted are the SRL measurements of precipitable water and cirrus optical depth. The correlation between retrieved PW and optical cirrus depth is clear. 
the MODIS instrument (http:// modarch.gsfc.nasa.gov /MODIS/) on the recently launched Terra satellite are needed to improve satellite sensitivity to cimus. Studies similar to that performed here are needed to determine the effectiveness of these new approaches to cirrus detection from satellite.

\section{Acknowledgments}

The authors wish to acknowledge the important efforts of numerous individuals in this effort: Bob Knutesen and others from the Space Science and Engineering Center of the University of Wisconsin for several sets of data including the AERI-GOES retrievals, radiosonde, GPS , and standard meteorological data; Prentiss Moore and Don Penny of NASA/GSFC Wallops Flight Facility for radiosonde data from Andros Island; Brent Holben and the NASA/GSFC AERONET (AErosol RObotic NETwork) effort for use of a Cimel sun photometer and the processing of the data which are now part of the vast database of such measurements maintained at http://aeronet.gsfc.nasa.gov:8080/; Ed Eloranta for very helpful discussions on multiple scattering; and all the individuals who helped to make the deployment of the SRL to Andros Island successful: Martin Cadirola, Jeff Freemire, Fred Huegel, Gerry McIntire, Wallace McMillan, Steve Palm, Stacy Wise, Glenn Staley and Dan Wooten. And finally, the authors would like to acknowledge the support of Dr. Ramesh Kakar, head of NASA's Atmospheric Dynamics and Remote Sensing Program, which made this experiment possible.

\section{References}

[1] Ansmann, A., U. Wandinger, M. Riebesell, C. Weitkamp, W. Michaelis, 1992: Independent measurement of extinction and backscatter profiles in cirrus clouds by using a combined Raman elastic-backscatter lidar, App. Opt., 31, No. 33, 7113-7131.

[2] Bohren, C. F. and D. R. Huffman, Absorption and Scattering of Light by Small Particles, Wiley Interscience Publication, 530 p. (1980)

[3] Beutler, G., I.I. Mueller, and R.E. Neilan, 1994: The International GPS Service for Geodynamics (IGS): Development and Start of Official Service on January 1, 1994, Bulletin Geodesique, 68, 1.

[4] Demoz, B., D. Starr, D. Whiteman, K. Evans, D Hlavka, R. Peravali1, 2000: Raman LIDAR detection of cloud base, submitted to Geophys. Res. Lett.

[5] DeSlover, D. H., W. L. Smith, P. K. Piironen and E. W. Eloranta, 1999: A methodology for measuring cirrus cloud visible-to-infrared spectral optical depth ratios, J. Atmos. Ocean. Tech., 16, 251-262.

[6] Duan, J.M., M. Bevis, P. Fang, Y. Bock, S.R. Chiswell, S. Businger, C. Rocken, F. Soldheim, R.H. Ware, T.A. Hering, and R.W. King, 1996: Remote Sensing Atmospheric Water Vapor using the Global Positioning System, J. Appl. Meteor., 35. 830-838.

[7] Ellingson, R. G., W. J. Wiscombe, 1996: The spectral radiance experiment (SPECTRE): Project description and sample results, Bull. Amer. Meteor. Soc., 77, 1967-1985

[8] Eloranta, E. W., Practical model for the calculation of multiply scattered lidar returns, Appl. Opt., 37,12, 24642472 .

[9] Evans K. D., S. H. Melfi, R. A. Ferrare, D. N. Whiteman, 1997: Upper tropospheric temperature measurements with the use of a Raman lidar, App. Opt, 36 2594-2602

[10] Feltz, Wayne F., William L. Smith, Robert O. Knuteson, Henry E. Revercomb, Harold M. Woolf, and H. Ben Howell, 1998: Meteorological applications of temperature and water vapor retrievals from the ground-based Atmospheric Emitted Radiance Interferometer (AERI). J. of Appl. Meteor., 37, 857-875. 
[11] Ferrare, R.A., S. H. Melf, D. N. Whiteman, K. D. Evans, 1992: Raman Lidar measurements of Pinatubo aerosols over southeastem Kansas during November - December, 1991, Geophys. Res. Lett., 19, 1599-1602.

[12] Ferrare, R.A., S.H. Melfi, D.N. Whiteman, K.D. Evans, F.J. Schmidlin and D.O'C. Starr, 1995: A Comparison of Water Vapor Measurements made by Raman Lidar and Radiosondes, J. Atmos. Ocean. Tech., 12, 1177-1195.

[13] Ferrare, R. A., S. H. Melfi, D. N. Whiteman, K. D. Evans, R. Leifer, 1998: Raman lidar measurements of aerosol extinction and backscattering 1. Methods and comparisons. J. Geo. Phys. Res., 103, D16, 19663-19672.

[14] Goldsmith, J. E. M., F. H. Blair, S. E. Bisson, D. D. Turner, 1998: Turn-key Raman lidar for profiling atmospheric water vapor, clouds, and aerosols, Appl. Opt., 37, 4979-4990.

[15] Grenfell, T. C., S. G. Warren, 1999: Representation of a nonspherical ice particle by a collection of independent sphere for scattering and absorption of radiation, J. Geophys. Res., 104, D24, 31,697-31,709

[16] Macke, A.,P. N. Francis, G. M. McFarquhar, S. Kinne, 1998: The role of ice particle shapes and size distributions in the single scattering properties of cirnus clouds, J. Atmos. Sci., 55, $2874-2883$.

[17] Melfi, S. H., D. N. Whiteman, R. A. Ferrare, 1989: Observation of atmospheric fronts using Raman lidar moisture measurements, J. App. Meteor., 28, 789-806.

[18] Melfi, S. H., K. D. Evans, J. Li, D. Whiteman, R. Ferrare, G. Schwemmer, 1997:Observation of Raman scattering by cloud droplets in the atmosphere, App. Opt., 36, 15, 3551-3559.

[19] Prabhakara, C., R. S. Fraser, G. Dalu, M. C. Wu, R. J. Curran, 1988: This cirrus clouds: seasonal distribution over oceans deduced from Nimbus-4 IRIS, J. Appl. Meteor., 27, 379-399.

[20] Pruppacher, H.R., and J.D. Klett, 1997: Microphysics of Clouds and Precipitation. Kluwer Academic Publishers, $954 \mathrm{pp}$.

[21] Revercomb, H. E., W. F. Feltz, R. O. Knuteson, D. C. Tobin, P. F. W. van Delst, and B. A. Whitney, Accomplishments of the Water Vapor IOPs: An Overview, Proceedings of the Eighth Atmospheric Radiation Measurement (ARM) Science Team Meeting, March 23-27, 1998 Tucson, Arizona.

[22] Ramamurthy, M. K. and B. F. Jewett, 1999: Ensemble Prediction of Hurricane Opal's Track and Intensity, Proceedings of the American Meteorology Society's 23rd Conference on Hurricanes and Tropical Meteorology, 10 15 January, 1999.

[23] Reid J. S., T. F. Eck, S. A. Christopher, P. V. Hobbs, B. Holben, 1999: Use of the Angstrom exponent to estimate the variability of optical and physical properties of aging smoke particles in Brazil, J. Geophys. Res. - Atmos. 104: (D22) 27473-27489.

[24] Sassen, K. and B. S. Cho, 1992: Subvisual-thin cirnus lidar dataset for satellite validation and climatological research, J. Appl. Meteor., 31, 11, 1275-1285.

[25] Sherlock, V., A. Hauchecome and J. Lenoble, 1999: Methodology for the independent calibration of Raman backscatter water-vapor lidar systems, App. Opt., 38, 5816-5837.

[26] Smith W. L., W. E. Feltz, R. O. Knuteson, H. E. Revercomb, H. M. Woolf, H. B. Howell, 1999: The retrieval of planetary boundary layer structure using ground-based infrared spectral radiance measurements, J. Atmos. Ocean. Tech. 16: (3) 323-333.

[27] Suggs, R. J., G. J. Jedlovec, A. R. Guillory, 1998: Retrieval of geophysical parameters from GOES: evaluation of 
a split-window technique, J. Appl. Meteor., 37, 1205-1227.

[28] Takano, Y. and K-N Liou, 1989: Solar radiative transfer in cirrus clouds. Part I: Single-scattering and optical properties of hexagonal ice crystals, J. Atmos. Sci., 46, No. 1, 3-19.

[29] Turner, D. D., W. F. Feltz, R. A. Ferrare, 2000: Continuous Water Profiles from Operational Ground-based Active and Passive Remote Sensors, Bull. Amer. Soc., accepted.

[30] Wandinger, U., 1998: Multiple-scattering influence on extinction- and backscatter-coefficient measurements with Raman and high-spectral-resolution lidars, Appl. Opt., 37, 3, 417-427.

[31] Warren, S. G., 1984: Optical constants of ice from the ultraviolet to the microwave., Appl. Opt., 23, 1206-1225.

[32] Whiteman, D.N., S.H. Melfi, and R.A. Ferrare, 1992: Raman lidar system for the measurement of water vapor and aerosols in the earth's atmosphere, Appl. Opt., 31, No. 16, 3068-3082.

[33] Whiteman, D. N., S. H. Melfi, 1999: Cloud liquid water, mean droplet radius and number density measurements using a Raman lidar, J. Geophys. Res., Vol 104 No. D24 December 27, 31411-31419

[34] Wylie, D. P., and W. P. Menzel, 1989: Two years of cloud cover statistics using VAS, J. Climate, 2, 380-392.

[35] Wylie, D., P. Piironm, W. Wolf, E. Eloranta, 1995: Understanding Satellite Cirrus Cloud Climatologies with Calibrated Lidar Optical Depths, J. Atmos. Sci., 52, 23, 4327-4343.

[36] Yang, P., K. N. Liou, W. P. Amott, 1997: Extinction efficiency and single-scattering albedo for laboratory and natural cirrus clouds, J. Geophys., Res., 102, D18, 21,825-21,835. 